\title{
Prevalence of Tobacco Consumption and Its Contributing Factors among Students of a Private Medical College in Belgaum: A Cross Sectional Study
}

\author{
Patel Jay $^{1}$, Mubashir Angolkar ${ }^{1}$, Shruti Murthy ${ }^{1}$, Maheswar D Mallapur ${ }^{2}$
}

\begin{abstract}
BACKGROUND: Tobacco consumption epidemic is one of the biggest public health threats that the world is facing and attracts the attention of researchers to identify the cause for the same in specific groups. Medical students act as mentors to fight against tobacco use, but several reports suggest that a good number of medical undergraduates are themselves addicted to tobacco use. Thus, the objective of the study was to determine the prevalence of tobacco consumption and its association with various factors among undergraduate medical students.

MATERIALS AND METHODS: A cross-sectional study was conducted on 372 undergraduate medical students from first to fourth year during November 2013 to January 2015. A pre-designed, pre-tested, structured and self-administered questionnaire was used. Statistical analysis was done using SPSS software version 16. Data was analyzed for percentage, Chi-square test and regression analysis to find association between tobacco use and various independent variables.

RESULT: The mean age of the participants was $21.2(S D=2.28)$ years with a male-female ratio of 1.92:1. The prevalence of tobacco use was $27.1 \%(n=101)$. The overall prevalence of smoking and smokeless tobacco use was $22.6 \%(n=84)$ and $7.8 \%(n=29)$ respectively. The prevalence of current tobacco use was 24.2\% (n=90). Among the ever tobacco users, about 3\% $(n=11)$ had quit using tobacco. Tobacco consumption was observed to be significantly associated with male gender ( $p<.001)$, increasing age $(p<0.01)$, residing in hostels ( $p<.001)$ and with a parental history of using tobacco $(p<.001)$.

CONCLUSION: The prevalence of tobacco use in smoking and smokeless form among undergraduate medical students was high.This has important implications in the strict implementation and monitoring of smoking-related rules in hostels of medical colleges, especially those related to peer-support.
\end{abstract}

KEYWORDS: Tobacco, Smoking, Medical students

DOI: http://dx.doi.org/10.4314/ejhs.v26i3.3

\section{INTRODUCTION}

The tobacco epidemic is one of the biggest public health threats the world is facing today. It kills nearly 6 million people a year. This figure is expected to increase to 10 million deaths per year by 2020 , with 7 million of these deaths to occur in China and India (1).

In India, tobacco kills 0.8-1 million people each year and many of these deaths will occur in people who are very young. It has been estimated that an average of five-and-a-half minutes of life is lost for each cigarette smoked (2).

Karnataka shows a prevalence of $28.2 \%$ of tobacco consumption. Among users, $12 \%$ use tobacco in the form of cigarettes while $19 \%$ use it in smokeless tobacco form (3). A sentinel survey in Karnataka reports about $50 \%$ of males and $16 \%$ of females in rural areas and $32.7 \%$ of males and $8.5 \%$ of females in urban areas to be tobacco users. In both urban and rural areas, about twothirds of male users smoke, while most female users chew tobacco (4).

\footnotetext{
${ }^{1}$ JNMC, Public Health, KLE University, Karnataka, India

${ }^{2}$ JNMC, Community Medicine, KLE University, Karnataka, India

Corresponding Author: Patel Jay, Email:jaypate19753@gmail.com
} 
As future physicians, medical students will be advocates of 'Tobacco Control Programs'; so they should be trained to combat a social evil such as this. Hence, this study focused on the prevalence of tobacco consumption among medical students.

The primary objective of the study is to determine the prevalence of tobacco consumption among undergraduate medical students of Jawaharlal Nehru Medical College (JNMC), Belagavi, and to assess the association between tobacco consumption, socio-demographical factors, tobacco contacts and reasons for tobacco consumption.

\section{MATERIALS AND METHODS}

This study was undertaken among undergraduate medical students from first to fourth year in a medical college at Belagavi in North Karnataka in the year 2014. The sampling frame consisted of 800 medical students (200 in each undergraduate year). By taking the prevalence of tobacco consumption among medical students as $18 \%$ (6), relative error of 4 , the sample size was calculated using the formula $4 \mathrm{pq} / \mathrm{d}^{2}$. Thus, the sample size required was 369 . A total of 372 were taken such that there equal number of participants from each of the undergraduate phases. All the 800 undergraduate medical students were numbered and the required sample was selected by simple random sampling method. Equal numbers of participants (93) were selected from each of the four undergraduate years. A pre-designed, pretested, structured and self -administered questionnaire was used to collect data on sociodemographics (age, gender, parents' education, current residence, occupation, and income), personal history, tobacco consumption, tobacco use among peers and time spend with them, past history of tobacco use, reasons for initiation and cessation of tobacco use, parent history of tobacco consumption, source of information for tobacco use and hazards, and awareness of smokingrelated laws. Study participants were asked regarding their habits and duration of using smokeless tobacco like chewing tobacco, snuff inhalation, chewing guthkha etc. and were classified as (a) non-user: a person who had never used smokeless tobacco, (b) ever user: a person who was using smokeless tobacco in his/her life time before one year and is not using it at present and (c) current user: a person who is using smokeless tobacco at present. Participants who used tobacco in smoking form were classified as a) non-smoker: a person who has never smoked tobacco or smoked $<100$ cigarettes/beedies/hookahs in his/her life time, (b) ever-smoker: a person who had smoked $\geq 100$ cigarettes/beedies/hookahs in his/her life time before one year and is not smoking since last one year and (c) current smoker: a person who has smoked $>=100$ cigarettes/beedies/hookahs and is currently smoking every day (5).

Ethical clearance was obtained from JNMC Institutional Ethics Committee on Human Subject Research, and written informed consent was obtained from the study participants. All participants were given a unique identification code to maintain confidentiality. Data was entered into Microsoft Excel 2007 and analyzed using SPSS software v.16. Quantitative variables were summarized using mean and standard deviation and qualitative variables in percentages. Association between dependant and independent variables were done using Chi-Square test and regression analysis. A p-value less than .05 was considered as significant.

\section{RESULTS}

All the 372 participants completely filled out the questionnaire. The mean age of the participants was $21.18(\mathrm{SD}=2.28)$ years. The mean ages of female and male participants were $21.4(\mathrm{SD}=2.32$ years $)$ and $21.06(\mathrm{SD}=2.25)$ years respectively. Minimum and maximum ages of the study participants were 18 years and 25 years respectively. One-third of the participants $(n=115$, $30.9 \%$ ) were in the age group of 19-20 years. Males formed the relative majority $(\mathrm{n}=245$, $65.9 \%$ ) between both the genders. The majority of the parents were graduates $(n=240,64.5 \%)$. More than half of the participants $(n=211,56.7 \%)$ were residing in hostels at the time of the interview.

The overall prevalence of tobacco use was $27.1 \%(\mathrm{n}=101)$. The prevalence of current tobacco use was $24.2 \%(n=90)$. The overall prevalence of smoking and smokeless tobacco use was $22.6 \%$ $(\mathrm{n}=84)$ and $7.8 \% \quad(\mathrm{n}=29)$ respectively. The majority of the tobacco users were males $(n=85$, $94.4 \%)$, aged between $23-24$ years $(n=27 ; 7.2 \%)$, residing in hostels $(n=70 ; 77.8 \%)$, had peers who used tobacco $(\mathrm{n}=90 ; 24.2 \%)$ and negative parental tobacco use history $(\mathrm{n}=41 ; 45.6 \%)$. The majority 
of the parents of tobacco users were graduates $(n=240 ; 64.5 \%)$. There was a significant association between tobacco consumption and

Table 1: Socio-Demographic Characteristics of the Study Participants $(\mathrm{N}=372)$

\begin{tabular}{|c|c|c|c|c|c|}
\hline \multirow[t]{2}{*}{ Variables } & & \multirow{2}{*}{$\begin{array}{l}\text { Total } \\
\text { No }(\%)\end{array}$} & \multicolumn{2}{|c|}{ Current Tobacco use } & \multirow[t]{2}{*}{ p-value } \\
\hline & & & Yes $(\mathrm{N}=90)$ & No $(\mathrm{N}=248)$ & \\
\hline \multirow[t]{5}{*}{ Age (years) } & $\leq 18$ & $52(14.0)$ & $6(11.5)$ & $46(88.5)$ & \multirow[t]{5}{*}{$0.011 *$} \\
\hline & $19-20$ & $115(30.9)$ & $21(18.3)$ & $94(81.7)$ & \\
\hline & $21-22$ & $90(24.2)$ & $24(26.7)$ & $66(73.3)$ & \\
\hline & $23-24$ & $81(21.8)$ & $27(33.3)$ & $54(66.7)$ & \\
\hline & $\geq 25$ & $34(9.1)$ & $12(35.3)$ & $22(64.7)$ & \\
\hline \multirow[t]{2}{*}{ Gender } & Male & $245(65.9)$ & $85(34.7)$ & $160(65.3)$ & \multirow[t]{2}{*}{$<0.001^{\dagger}$} \\
\hline & Female & $127(34.1)$ & $5(3.9)$ & $122(96.1)$ & \\
\hline \multirow[t]{3}{*}{ Religion } & Hindu & $254(68.3)$ & $59(23.2)$ & $195(76.8)$ & \multirow[t]{3}{*}{0.698} \\
\hline & Muslim & $27(7.3)$ & $6(22.2)$ & $21(77.8)$ & \\
\hline & Christian & $91(24.5)$ & $25(27.5)$ & $66(72.5)$ & \\
\hline \multirow[t]{3}{*}{ Educational Status of Father } & High school & $13(3.5)$ & $3(23.1)$ & $10(76.9)$ & \multirow[t]{3}{*}{0.887} \\
\hline & Graduate & $240(64.5)$ & $60(25)$ & $180(75)$ & \\
\hline & Post graduate & $119(32.0)$ & $27(22.7)$ & $92(77.3)$ & \\
\hline \multirow[t]{3}{*}{ Educational Status of Mother } & High school & $56(15.1)$ & $16(28.6)$ & $40(71.4)$ & \multirow[t]{3}{*}{0.707} \\
\hline & Graduate & $240(64.5)$ & $56(23.3)$ & $184(76.7)$ & \\
\hline & Post graduate & $76(20.4)$ & $18(23.7)$ & $58(76.3)$ & \\
\hline \multirow[t]{4}{*}{ Occupation of Father } & Govt. Employee & $53(14.2)$ & $16(30.2)$ & $37(69.8)$ & \multirow[t]{4}{*}{0.50} \\
\hline & Businessman & $117(31.5)$ & $31(26.5)$ & $86(73.5)$ & \\
\hline & Private & $191(51.3)$ & $41(21.5)$ & $150(78.5)$ & \\
\hline & Farmer & $11(3)$ & $2(11.2)$ & $9(88.8)$ & \\
\hline \multirow[t]{3}{*}{ Socio-economic Status } & Class I & 89 (23.9) & $24(27)$ & $65(73)$ & \multirow[t]{3}{*}{0.743} \\
\hline & Class II & $260(69.9)$ & $60(23.1)$ & $200(76.9)$ & \\
\hline & Class III & $23(6.2)$ & $6(26)$ & $17(74)$ & \\
\hline \multirow{2}{*}{$\begin{array}{l}\text { Source of Residence } \\
(n=372)\end{array}$} & Hostelites & $211(56.7)$ & $70(33.2)$ & $141(66.8)$ & \multirow[t]{2}{*}{$<0.001^{\dagger}$} \\
\hline & Day Scholar & $161(43.3)$ & $20(12.4)$ & $141(87.6)$ & \\
\hline \multirow{4}{*}{$\begin{array}{l}\text { Peers Smoking } \\
(\mathrm{n}=372) \\
\text { Parental History }(\mathrm{n}=372)\end{array}$} & Yes & $323(86.8)$ & $90(27.9)$ & $233(72.1)$ & \multirow[t]{2}{*}{$<0.0001^{\dagger}$} \\
\hline & No & $49(13.2)$ & 0 & $49(100)$ & \\
\hline & Yes & $82(22)$ & $41(50)$ & $41(50)$ & \multirow[t]{2}{*}{$<0.001^{\dagger}$} \\
\hline & No & $290(78)$ & $49(16.9)$ & $241(83.1)$ & \\
\hline
\end{tabular}

$*,{ }^{\dagger}$ Significant $* \mathrm{p}<0.05 \quad{ }^{\dagger} \mathrm{p}<0.001$

Among the current tobacco users, 84\% ( $\mathrm{n}=76)$ were smokers while $10 \%(\mathrm{n}=9)$ used both tobacco forms. Eighty-seven percent $(n=323)$ of the participants' peers were smokers, and most of the participants $(\mathrm{n}=233 ; 87 \%)$ spent a mean duration variables like age, sex, parental history and source of residence of participants (Table 1). 
Table 2: Tobacco Use Characteristics among Current and Former Tobacco Users

\begin{tabular}{lll}
\hline Variable & Smoking $\mathbf{n}(\boldsymbol{\%})$ & Smokeless n* (\%) \\
\hline Ever Users $(\mathrm{n}=101 ; 27.1 \%)$ & $84(83.2 \%)$ & $29(28.8 \%)$ \\
Current Users $(\mathrm{n}=90 ; 24.1 \%)$ & $76(84.4 \%)$ & $23(25.6 \%)$ \\
Former Users $(\mathrm{n}=11 ; 0.3 \%)$ & $8(72.7 \%)$ & $6(54.5 \%)$ \\
Current Users & Mean (SD) & Mean (SD) \\
Number used/ day & $12.63(4.39)$ & $8.72(2.986)$ \\
Participant's age of initiation & $17.91(1.67)$ & $19.11(2.05)$ \\
Duration of use (years) & $4.18(1.838)$ & $3.0(1.283)$ \\
Former Users & Mean (SD) & Mean (SD) \\
Number used/ day & $5.4(2)$ & $4.3(0.6)$ \\
Age of initiation (in years) & $18.1(1.8)$ & $18.7(3)$ \\
Duration of use (in years) & $2(0.8)$ & $1.7(0.6)$ \\
\hline
\end{tabular}

*number of participants

As shown in Table 3, the most common reason for tobacco use initiation among smokers was relief of stress $(\mathrm{n}=84,84 \%)$ followed by peer influence $(\mathrm{n}=60,60 \%)$. Out of 11 participants who successfully quit tobacco use, parents' objection $(\mathrm{n}=8,72.7 \%)$ was the common reason reported for the cessation. All the participants were aware of the hazards of tobacco consumption. The most common information source was the media $(88.2 \%)$ followed by peers $(59.4 \%)$. The majority of the participants $(n=332,89.2 \%)$ were aware of the presence of laws prohibiting smoking in public places (Figure 1).

Table 3: Reason for Initiation and Cessation of Tobacco use among Study Participants

\begin{tabular}{lll}
\hline Variables & & No* $(\%)$ \\
\hline Reason for Initiation $\dagger$ & Peers Influence & $60(60)$ \\
$($ Both) & Parents Influence & $13(13)$ \\
$(\mathrm{n}=100)$ & TV/Movies Influence & $20(20)$ \\
& Status Symbol & $14(14)$ \\
& Imitation & $36(36)$ \\
& Relief of Stress & $84(84)$ \\
& Family Problem & $8(8)$ \\
Reason for Cessation $\dagger$ & Don't Know & $18(18)$ \\
$(\mathrm{n}=11)$ & Parents Objection & $8(72.7)$ \\
& Health Problem & $3(27.2)$ \\
& Awareness of Hazards & $5(45.4)$ \\
& Don't Know & $3(27.2)$ \\
\hline
\end{tabular}

*number of participants, Multiple Responses

The multiple logistic regression model between tobacco consumption and various independent factors (age, sex, parents' history of consuming tobacco and source of residence) showed that ages of 23 years and above $(\mathrm{p}<.001)$, males $(\mathrm{p}<.001)$ residing in hostels $(\mathrm{p}<.001)$ and parent history of tobacco use $(\mathrm{p}<.001)$ were significant (Table 4$)$. 
Table 4: Multiple Logistic Regression for Tobacco Consumption and its Contributing Factors.

\begin{tabular}{lllll}
\hline Risk Factors & & Adjusted Odds Ratio & 95\% Confidence Interval & p value \\
\hline & $19-20$ & 0.98 & $0.32-2.98$ & 0.985 \\
Age (years) & $21-22$ & 2.11 & $0.68-6.48$ & 0.194 \\
& $23-24$ & 4.98 & $1.60-15.49$ & $<0.01^{\ddagger}$ \\
& 225 & 6.36 & $1.62-24.94$ & $<0.01^{\ddagger}$ \\
Sex (M/F) & 19.04 & $6.86-52.79$ & $<0.001^{\dagger}$ \\
Parent's History & 4.86 & $2.52-9.37$ & $<0.001^{\dagger}$ \\
Residence & 0.15 & $0.07-0.30$ & $<0.001^{\dagger}$ \\
(Day scholar/Hostelites) & & & \\
\hline
\end{tabular}

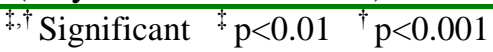

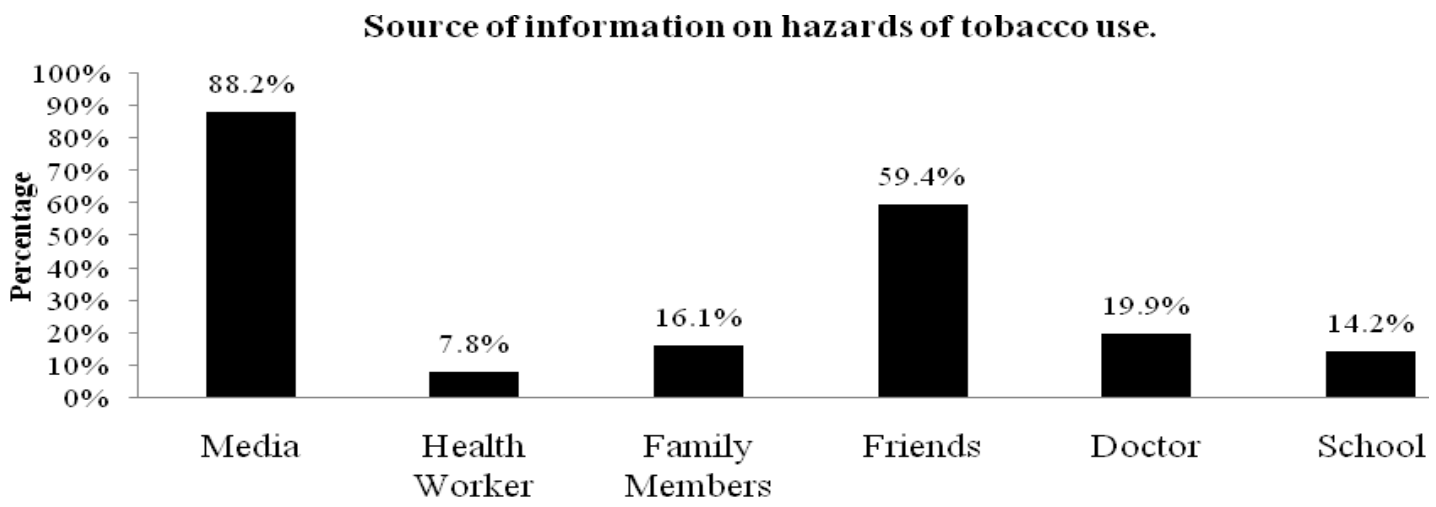

Source of Information

Figure 1: Source of Information on Hazards of Tobacco Use

\section{DISCUSSION}

The prevalence of tobacco use was $27 \%$ in this study. Among the study participants, the prevalence of current tobacco use was $24 \%$ of which $84 \%$ smoked tobacco while $25 \%$ chewed tobacco. Six percent of the participants were current users of smokeless tobacco. Twenty-three percent of the participants were ever smokers and $20 \%$ were current smokers.

In this study, $91 \%$ of the participants belonged to 18-24 years of age. Similar participant ages were reported from studies conducted to assess tobacco use among medical students in Kolkata, where $96 \%$ of students were between of 19-24 years of age (6), and Allahabad having 85\% of students aged between 18-24 years (7). In our study, overall $66 \%$ were male participants.
Similarly, the study conducted in Allahabad (7) reported $67 \%$ of the participants being males.

This study observed that $20 \%$ of the medical students used tobacco in the form of smoking, while $6 \%$ of them used it in smokeless form. Our findings for smoking were higher compared to studies among medical students conducted in 6 developing countries (Ever smokers: 21\%; Current Smokers: 14\%) (8) and in Kolkata (15\%) (6). The prevalence of smokeless tobacco use was slightly higher (7\%) in the study in Kolkata (6) compared to our study. These differences could be attributed to the varying definitions used in both the studies $(8,6)$. In our study, $3 \%$ were past tobacco users which is similar to the study conducted in Lucknow (8) showing $4 \%$ of ever users who had left current tobacco consumption. This finding 
shows the role of age as an important contributing factor for the initiation of tobacco consumption at an early stage. Thus, strict monitoring and implication of tobacco prohibition rules should be carried out in hostel and education centers (9).

About $7.2 \%$ of the tobacco use was found among age group of 23-24 years in our study. These findings were lower as compared to the cross sectional study conducted in Manglore which reported $6.35 \%$ of tobacco users were in age group of 22-23 years (10).

About $35 \%$ of male and $4 \%$ of the female participants in our study were using tobacco. These findings were much higher compared to a multicentre study in developing countries which reported $20 \%$ and $2 \%$ tobacco use rates among Indian medical students. Evidence suggests that male medical students have significantly higher tobacco use rates than female students in all developing countries due to conservative nature of and offence taken by societies towards female smoking (8). However, medical students in Lucknow (11) reported a prevalence of $25 \%$ and $11 \%$ in smoking and smokeless forms respectively. Thus, strict tobacco cessation program should be more targeted among both genders (9).

In a study conducted in West Bengal (12), it was observed that $38 \%$ of the students have a familial history of smoking. This proportion was higher compared to that found in our study. A study conducted in Andhra Pradesh (13) shows that $38 \%$ of the participants has a positive history of parents' consumption of tobacco in the form of smoking. This shows the important role that family history plays in initiation of tobacco consumption, which should be considered during designing tobacco cessation programmes (9).

In this study, $57 \%$ of the study participants were hostelites which is almost similar to the study done in New Delhi (14) revealing that 68\% of students were hostelites. Another study conducted in Central India (15) shows that $87 \%$ of students were hostelites during the study period. These findings reveal influence of environment on the tobacco consumption among medical students which should be targeted and intervened properly (9).

In this study, almost $90 \%$ of the medical students were aware that smoking at public places is prohibited by laws. This is similar to a study conducted in Coastal South India (10) where 89\% of students were aware of the prohibition of smoking at public places.

In this study, multiple logistic regression model shows significant result between tobacco consumption among medical students and different contributing factors like age, sex, parents' history of consuming tobacco and source of residence.

In this study, $73 \%$ of the students stated parents' objection as the common reason for quitting tobacco followed by awareness of hazards $(45 \%)$. Less than one-third of the participants quit tobacco because of health problems. A study conducted in Coastal South India (8) found more than two-thirds of medical students willing to quit tobacco because of knowing the ill-effects of tobacco consumption. This finding shows the role of health education in cessation of tobacco consumption which should be more focused on (9).

In present study, $84 \%$ of students started tobacco consumption for the stress relief followed by peer's influence $(60 \%)$. Study conducted in Kolkata (6) shows curiosity (44\%) as common reason for initiation of tobacco consumption followed by Peer pressure (29\%) among medical students. Study conducted in Andhra Pradesh (13) shows $68 \%$ of peer's influence among the participants who were consuming tobacco in form of smoking. Thus stress reduction, peer education program and intervening influencing factors should be targeted (9).

The study had some weaknesses. This was a cross-sectional study conducted in one medical college which could potentially affect generalizability of the results. However, we assume this may not be a concern as our participant characteristics and findings are similar to other studies performed among medical undergraduates. There were more males compared to females, and hence, differentials in tobacco use and odds ratio should be interpreted with caution. Although we collected data on socio-economic status, which is an important factor (8), we could not use it because more than $40 \%$ participants did not know about their family earnings. A multi-site longitudinal study is warranted to confirm the reliability of the findings of potential factors associated with tobacco use including the 
dynamics of tobacco use through the phases of medical education.

Finally, the study concludes that the prevalence of tobacco use was found among onethird of medical students. The majority of them were males, smoked tobacco, resided in hostels, spent time with peers who were tobacco users and had a positive parental history of tobacco use. This finding may have important implications in the strict implementation and monitoring of smokingrelated rules in hostels of medical colleges. Such strategies should be targeted towards students, including their peers, at the final phases $\left(3^{\text {rd }}\right.$ and $4^{\text {th }}$ years) of Bachelor of Medicine and Bachelor of Surgery (MBBS). Stress, unfortunately, has become an inevitable side effect among medical students today. Student counselling and tobacco alternatives for hard-to-quit tobacco users should be explored in addition to penalties for such users. Awareness of hazards is one of the key prevention strategies of tobacco use among medical students. The impact of health education, mass communication, Information, Education and Communication (IEC) activities along with strict legislative actions should be employed in intervention studies among medical students from the time of joining the medical course. Finally, the role of parents in their children's tobacco habits should be identified and acknowledged so that IEC efforts targeted towards them can definitely impact the behavior of the latter.

\section{ACKNOWLEDGEMENT}

We sincerely thank all the medical undergraduates for their participation in the study, Dr. Kumar Sumit for technical support and all our colleagues for their continuous support.

\section{REFERENCES}

1. World Health Organization (WHO). Ort EP. Making a difference-World Health Report, 1999. Available from: www.who.int/whr/1999/en/. (Accessed on 19 October, 2013)

2. World Health Organization (WHO). Global Adult Tobacco Survey (GATS) fact sheet 2009-2010. Available from: www.who.int/mediacentre/factsheets/fs339/en lindex.htm. (Accessed on 30 October, 2013)
3. Tobacco use still a health hazard. Deccan Herald, 2014 Oct 29; 5.

4. Gupta PC, Ray CS. Tobacco, education \& health. Indian J Med Res, 2007; 126 (4): 28999.

5. Centre for Disease Control and Prevention (CDC). NHIS-Adult Tobacco Use information. Available from: www.cdc.gov/nchs/nhis/tobacco/tobacco_glos sary.htm. (Accessed on 13 April, 2014)

6. Chatterjee T, Haldar D, Mallik S, Sarkar GN, Das S, Lahiri SK. A study on habits of tobacco use among medical and non medical students of Kolkata. Lung India, 2011; 28 (1): 5-10.

7. Mehrotra R, Chaudhary A, Pandya S, Mehrotra KA, Singh M. Tobacco Use by Indian Medical Students and the Need for Comprehensive Intervention Strategies. Asian Pac J Cancer Prev, 2010; 11: 349-52.

8. Sreeramareddy CT, Suri S, Menezes RG. Substance Abuse Treatment, Prevention and Policy 2010. Available from: www.substanceabusepolicy.com/content/5/1/2 9.

9. Chezhian C, Murthy S, Prasad $\mathrm{S}$ et al. Exploring factors that influence smoking initiation and cessation among current smokers. J Clin Diagn Res, 2015; 9 (5): 8-12.

10. Ganesh S, Subba SH, Unnikrishnan B, Jain A, Badiger S. Prevalence and Factors Associated with Current Smoking Among Medical Students in Coastal South India. Kathmandu University Medical Journal, 2011; 9 (36): 233-37.

11. Kumari R, Nath B. Study on the use of tobacco among male medical students in Lucknow, India. Indian J Community Med, 2008; 33 (2): 100-3.

12. Basu M, Das P, Mitra S, Ghosh S, Pal R, Bagchi S. Role of family and peers in the initiation and continuation of smoking behavior of future physicians. $J$ Pharm Bioallied Sci, 2011; 3 (3): 407-11.

13. Yerpude P, Jogdand K.S. Study of determinants of smoking habit among medical students. Pravara Medical Review, 2011; 3 (2): $16-9$.

14. Aggarwal S, Sharma V, Randhawa H, Singh $\mathrm{H}$. Knowledge, attitude and prevalence of use 
of tobacco among medical students in India: A single centre cross sectional study. Annals of Tropical Medicine and Public Health, 2012; 5 (4): 327-9.

15. Selokar DS, Nimbarte S, Kukde MM, Vasant $\mathrm{W}$. Tobacco use amongst the male medical students, Wardha. International Journal of Biological \& Medical Research, 2011; 2 (1): 378-81. 